\title{
Características económicas de complicaciones en pacientes con virus de inmudeficiencia humana hospitalizados
}

\author{
Margarita Echeverry* \\ Carlos Eduardo Herrera-Cano** \\ Carmen Luisa Betancur-Pulgarín ${ }^{* * *}$
}

ISSN 1794-9831

E-ISSN 2322-7028

Vol. 14 No. 1

Ene - Jun 2017

Cúcuta, Colombia

Recibido:

24 de Mayo de 2016

Aprobado:

27 de Octubre de 2016

${ }^{*}$ Enfermera.

Especialista en

Auditoría en

Servicios de Salud,

Gerencia en Salud

\section{RESUMEN}

Objetivo: determinar las características demográficas y económicas de las complicaciones que generan hospitalizaciones, en los pacientes del programa de control de la infección causada por el virus de la inmunodeficiencia humana, en una entidad promotora de salud privada del Quindío, durante el periodo julio 2012 - julio 2013. Materiales y Métodos: investigación cuantitativa, descriptiva, en una población de 52 usuarios, con una muestra de 31 pacientes que estuvieron hospitalizados. Se aplicó el instrumento Complicaciones en Pacientes con Síndrome de Inmunodeficiencia Humana Hospitalizados, validado por cinco expertos, para analizar variables sociodemográficas, clínicas y de costos. Resultados: se encontraron más hombres que mujeres en un $16 \%$, edad mínima de 21 años y máxima de 62. Más de la mitad de los pacientes viven en Armenia. La proporción más alta de hospitalización por complicaciones correspondió al municipio de Calarcá con un $75 \%$, seguido de Armenia con un $67 \%$ y Montenegro con un $41 \%$. Los diagnósticos que generan mayores costos fueron la toxoplasmosis y la neumonía, seguidas del linfoma no hodking, en pacientes no adherentes al programa. Conclusión: las complicaciones de mayor costo fueron toxoplasmosis y neumonía -más frecuentes en hombres-, las cuales tienen un alto costo tanto para los pacientes como para sus familias, al igual que para para las instituciones que cubren los servicios de este grupo de personas. Teniendo en cuenta la susceptibilidad de esta población a contraer patologías, que en otras circunstancias resultan de fácil manejo, es recomendable mantener la proyección hacia la prevención.

PALABRAS CLAVE: costo de enfermedad, hospitalización, síndrome de inmunodeficiencia adquirida, virus de la inmunodeficiencia humana ${ }^{* * * *}$.

\section{Para citar este artículo / Para citar este artigo/ To reference this article /}

Echeverry M, Herrera-Cano CE, Betancur-Pulgarín CL. Características económicas de complicaciones en pacientes con virus de inmudeficiencia humana hospitalizados. Rev. cienc. cuidad. 2017; 14(1): 23-39.

Ocupacional, y

Farmacodependencia.

Coordinadora -

Docente. Programa

Administrativo en

Salud. Instituto

INEC. Pereira,

Colombia. Correo

electrónico:

echeverrymargarita@

institutoinec.edu.co

${ }^{* *}$ Médico.

Especialista en

Auditoría en Salud.

Docente. Centro de

Posgrados. Fundación

Universitaria del

Área Andina. Pereira

Colombia. Correo

electrónico: carlos.

herrera@nuevaeps.

com.co

${ }^{* * *}$ Enfermera

Magister en Cuidado

Adulto y Anciano,

Especialista

en Docencia

Universitaria y

Epidemiologia.

Docente Asociada.

Centro de Posgrados

Coordinadora

Programa

Epidemiología

Investigadora

Lider Grupo

ZIPA. Fundación

Universitaria del

Área Andina.

Pereira, Colombia.

Correo electrónico:

cbetancur@,

areandina.edu.co

${ }^{* * * * *}$ Descriptores

en Ciencias de la

Salud (DeCS), en la

página http://decs.

bvs.br/E/homepagee

htm de la Biblioteca

Virtual en Salud del proyecto BIREME,

de la Organización

Mundial de la Salud

y de la Organización

Panamericana de la

Salud. 
ISSN 1794-9831

E-ISSN 2322-7028

Vol. 14 No. 1

Ene - Jun 2017

Cúcuta, Colombia

\section{Economic characteristics of complications in hospitalized patients with human immunodeficiency virus (HIV)}

\section{ABSTRACT}

Objective: to determine the demographic and economic characteristics of the complications generated by hospitalizations, in patients from the control program of infections caused by the human immunodeficiency virus, in an entity that promotes private health in Quindio during the period of July 2012- July 2013. Materials and Methods: quantitative-descriptive research, in a population of 52 users, with a sample of 31 patients that were hospitalized. The Complication in Patients Hospitalized with Syndrome of Human Immunodeficiency virus instrument was administered, which has been validated by 5 experts, to analyze socio-demographics, clinics and cost variables. Results: more men than women were found by $16 \%$, minimum age 21 and maximum age 62 . More than half of the patients live in Armenia, Quindio. The highest proportion of hospitalization caused by complications corresponds to the Calarca district with $75 \%$, followed by Armenia with 67\%, and Montenegro 41\%. The diagnostics that generated higher expenses were toxoplasmosis and pneumonia, followed by non-hodgkin lymphoma, in patients out of the program. Conclusion: the complications with higher expenses were toxoplasmosis and pneumonia -more frequent in men-, which have a higher cost for both the patients and their families, as well as for the institutions that cover the services for this group of people. Considering the susceptibility of this population to get diseases, that in other circumstances could be easily handled, it is recommended to keep projection towards prevention.

KEYWORDS: cost of illness, hospitalization, acquired immunodeficiency syndrome, human immunodeficiency virus (HIV). 


\section{Características económicas de complicações em pacientes hospitalizados com vírus da imunodeficiência humana}

\section{RESUMO}

Objetivo: determinar as características demográficas e económicas das complicações que geram hospitalizações, nos pacientes do programa de controle da infeção causada pelo vírus da imunodeficiência humana, numa entidade promotora de saúde privada do Estado QuindíoColômbia, durante o período julho 2012 - julho 2013. Materiais e Métodos: pesquisa quantitativa, descritiva, utilizando uma população de 52 usuários, com uma amostra de 31 pacientes que estiveram hospitalizados. Aplicou-se o instrumento Complicações em Pacientes Hospitalizados com Síndrome da Imunodeficiência Humana, validado por cinco especialistas, para analisar variáveis sóciodemográficas, clínicas e de custos. Resultados: encontraram-se num $16 \%$, mais homens do que mulheres, com idade mínima de 21 anos e máxima de 62 . Mais da metade dos pacientes moravam na capital do estado Armenia. A proporção mais alta de hospitalização por complicações correspondeu ao município de Calarcá, com um $75 \%$, seguido de Armenia com um $67 \%$ e Montenegro com um $41 \%$. Os diagnósticos que geram maiores custos foram a toxoplasmose e a pneumonia, seguidas do Linfoma não-Hodgkin (LNH), em pacientes não aderentes ao programa. Conclusão: as complicações de maior custo foram toxoplasmose e pneumonia -mais frequentes em homens-, as quais tem um custo elevado tanto para os pacientes quanto para suas famílias, da mesma forma que para as instituições que cobrem os serviços deste grupo de pessoas. Tendo em conta a susceptibilidade dessa população em contrair patologias, que em outras circunstancias resultam de fácil manejo, é recomendável manter a projeção para a prevenção.

PALAVRAS-CHAVE: efeitos psicossociais da doença, hospitalização, síndrome de imunodeficiência adquirida, vírus da imunodeficiência humana (HIV). 
ISSN 1794-9831

E-ISSN 2322-7028

Vol. 14 No. 1

Ene - Jun 2017

Cúcuta, Colombia

\section{INTRODUCCIÓN}

$\mathrm{D}$ esde que se reportaron los primeros casos del síndrome de inmunodeficiencia adquirida (SIDA) en 1981, la infección por el virus de la inmunodeficiencia humana (VIH) ha crecido en proporciones pandémicas. En la actualidad, la infección es considerada como una enfermedad crónica, cuyas consecuencias psicológicas y sociales generan costosas y dolorosas pérdidas para el paciente, el sistema y la sociedad (1-2).

Se tiene como referente que el VIH se originó en los Estados Unidos en la década de los 80, época de protestas contra la guerra de Vietnam, la discriminación racial y la incursión de nuevas ideologías como el amor libre, lo que originó una revolución sexual, condición en la cual salieron a la luz pública cerca de 17 millones de personas de la comunidad gay americana (3).

Del mismo modo, se produjo un aumento en el consumo de drogas como la marihuana, el dietilamida del ácido lisérgico (LSD), las anfetaminas, la cocaína y, posteriormente, el crack y la heroína, lo que consecuentemente se encontró directamente relacionado con la propagación de esta enfermedad. Para mediados de la década de los ochenta, llegaron a los hospitales norteamericanos con patologías no esperadas (4).

El SIDA fue reconocido en 1981 en los EE. UU. por el Center for Disease Control and Prevention (CDC), ya que se encontró una neumonía por Pneumocystis jiroveci en cinco varones homosexuales previamente sanos y un sarcoma de Kaposi en 26 personas de esta población. Sin embargo, fue en 1983 cuando se aisló el virus de la inmunodeficiencia humana (VIH). Este agente etiológico pertenece a la familia de los retrovirus humanos: retroviridae, dentro de la familia lentivirus, siendo aisladas dos formas del VIH denominadas virus responsable de la epidemia de SIDA a nivel mundial VIH-1 y el tipo dos endémico en África Oriental y menos agresivo VIH-2 (5).

Muy pronto, los médicos investigadores concluyeron que se trataba de una deficiencia inmunológica, es decir, de una falta de defensas en el organismo ante los agentes infecciosos; de ahí el nombre de Inmunodeficiencia Adquirida o SIDA para identificar la enfermedad. Más adelante observaron que la mayor parte de los afectados eran hombres jóvenes homosexuales y que muchos eran adictos a las drogas intravenosas; al mismo tiempo se presentaron casos de SIDA entre personas hemofílicas que habían recibido transfusiones de sangre para el tratamiento de su enfermedad (6).

Estas observaciones llevaron a concluir que el mal estaba asociado con la práctica del homosexualismo y con el contacto con sangre de los enfermos a través de las jeringas y las transfusiones. De ahí el concepto de que el VIH fue, en sus orígenes, una epidemia que ocurría fundamentalmente entre los homosexuales masculinos y los drogadictos por inyección, mientras que las mujeres se encontraban al margen de esta (7).

Así mismo, se relaciona con la detección de varios casos de neumonía y sarcoma de Kaposi, especialmente en pacientes homosexuales, en los que se identifica una deficiencia de células sanguíneas con un comportamiento similar en cada uno de ellos; esta aparición de infecciones, muestra la capacidad del VIH de destruir los sistemas inmunológicos de los infectados, favoreciendo el desarrollo de patologías infeccionas que, posteriormente, se volvían crónicas y que daban paso a nuevas enfermedades como hepatitis víricas, erupciones gigantes de herpes genital o infecciones por virus altamente agresivos como el citomegalovirus, que atacaba los pulmones y el aparato digestivo del enfermo (8).

También se destacaba la presencia de manchas color rosa en la piel, asociadas a la tendencia homosexual de la mayoría de los afectados como inmigrantes, receptores de transfusiones sanguíneas, personas que se inyectaban drogas y mujeres heterosexuales vinculadas epidemiologicamente a la prostitución o esposos altamente promiscuos. Así, en 1984, se empezó a considerar la enfermedad como epidemia, al estudiar un grupo de personas que habían tenido parejas en común y que respondían a ciertos factores de riesgo también en común (9).

En los años 90 comenzó a producirse un aumento de la transmisión heterosexual, en donde era de 2 a 10 veces más probable que la mujer fuese infectada, conviertiendose internacionalmente en el grupo más susceptible. En consecuencia, un número cada vez mayor de mujeres y niños se infectó, equiparándose con la cifra de hombres (7). 
Pese a que los datos epidemiológicos internacionales más recientes indican que el porcentaje mundial de personas que viven con el VIH se estabilizó desde el año 2000 y que la tasa estimada de mortalidad por SIDAdisminuyó, debido a los avances farmacológicos y al acceso al tratamiento antirretrovírico, estas tendencias aún son desiguales en diferentes regiones del mundo e indican la imperativa necesidad de impulsar avances integrales que, desde el marco de políticas públicas, garanticen el acceso a los servicios preventivos y curativos, manejo adecuado de la enfermedad de acuerdo con el nivel asistencial y el enfoque de programas de prevención de la enfermedad y de promoción de la salud (10).

El SIDA es ocasionado por un retrovirus VIH, de transmisión sexual y transfusión sanguínea, se presenta en varias fases y lleva a la muerte. La infección por VIH/SIDA afecta de manera directa a los linfocitos T CD4 (células sanguíneas que ayudan a coordinar la respuesta inmunitaria al estimular a otros inmunocitos) bajando la respuesta inmune y dejando como consecuencia una alta vulneravilidad frente a la presencia de infecciones intercurrentes o el desarrollo de células cancerígenas. Esta es una enfermedad inmunodepresora, de impacto socio económico y sanitario (11).

El virus tiene una prodigiosa capacidad de mutar, lo que explica en parte el hecho de que en más de veinte años no se haya conseguido encontrar una vacuna para erradicarlo; tiene el poder de destruir los linfocitos $\mathrm{T}$, células responsables de producir inmunidad en el organismo y la capacidad de estar presente, sin ocasionar signos, ni síntomas, en el paciente, durante años y a veces por décadas (12).

Esta enfermedad es considerada la sexta causa de muerte en personas mayores de 25 años y actualmente millones de personas viven con VIH/SIDA, entre ellos menores de 15 años. Las bacterias comunes, los hongos levaduriformes, los parásitos y los virus que generalmente no provocan enfermedades serias en personas con sistema inmunitario sano, pueden provocar enfermedades mortales en las personas con SIDA (13).

Los programas de atención a las infecciones de transmisión sexual, entre ellas el VIH/SIDA, son el resultado de la evolución investigativa y epidemiológica del mundo entero, en donde intervienen aspectos de orden médico, farmacológico y psicosocial, logrando avances importantes en su tratamiento, reduciendo de manera significativa la morbilidad y mortalidad, pasando y considerándose actualmente como una infección crónica (14).

El VIH/SIDA es una enfermedad de manejo médico, dada la efectividad del tratamiento antirretroviral; no obstante, hay que considerar que los fármacos antirretrovirales tienen una serie de efectos secundarios de carácter fisiológico y psicológico, como cefalea, convulsiones, dificultad para concentrarse, síntomas gastrointestinales, reacciones cutáneas, ansiedad, depresión e ideas suicidas. Los efectos secundarios de naturaleza psicológica suelen aparecer al comienzo del tratamiento y desaparecen entre la segunda y la cuarta semana (15).

Al ser aislado el agente causal del VIH/SIDA, la epidemiología dejó de hablar de grupos de riesgo e incorporó la noción de prácticas de riesgo. El descubrimiento del virus fue objeto de polémica social y condujo, durante la segunda década del siglo, al aislamiento social de los infectados, respuesta que tuvo lugar en la población por el miedo a contraer el virus y por el desconocimiento de las formas de contagio, con la falsa creencia de que cualquier contacto significaría el lastre de la enfermedad (16).

Poco a poco se comenzó a aislar el virus y se diseñaron pruebas para detectar anticuerpos contra él en la sangre. La aplicación de estas pruebas a las personas de alto riesgo como los homosexuales, las trabajadoras sexuales, los consumidores de drogas intravenosas y sus parejas, constituyó el primer paso para el control de la epidemia, porque permitió evitar el contagio a través de las transfusiones, eliminando los frascos de sangre infectada y evitando la reutilización de agujas de jeringa (17).

Día a día se fueron conociendo más casos en los cuales se contraía el virus sin importar la edad y los portadores desconocían su situación, siendo transmisores silenciosos. En 1985 se estandarizó la prueba llamada ELISA -ensayo inmunoenzimático para la detección de anticuerpos contra el virus de inmunodeficiencia humana tipo 1 y 2-, como método de detección del VIH y se inició su aplicación en todas las unidades de sangre antes de ser transfundidas, asi como en las poblaciones con comportamientos de riesgo (18).
ISSN 1794-9831

E-ISSN 2322-7028

Vol. 14 No. 1

Ene - Jun 2017

Cúcuta, Colombia 
ISSN 1794-9831

E-ISSN 2322-7028

Vol. 14 No. 1

Ene - Jun 2017

Cúcuta, Colombia
Se estima que se puede brindar a las personas en esta condición una vida cada vez más larga y productiva, teniendo en cuenta todos los factores que involucran al paciente frente a la evolución propia de la enfermedad, con el fin de evitar la presentación de complicaciones asociadas. El VIH/SIDA sigue siendo un importante problema de salud pública mundial, puesto que cobró más de 34 millones de vidas hasta diciembre del $2014(7,19)$.

A finales de 2014 había 36,9 millones de personas infectadas por el VIH en todo el mundo, de las cuales 2 millones contrajeron el VIH en ese mismo año. El África Subsahariana, donde se reportaron 25,8 millones de personas infectadas por el VIH, es la región más afectada. Casi el $70 \%$ del total mundial de nuevas infecciones ocasionadas por este virus se registra en esta región (19).

África continúa siendo el continente más afectado, con 22 millones de enfermos, y se considera que en las Américas hay más de tres millones de afectados. En Honduras, el VIH/SIDA representa una preocupación para el Estado y la sociedad, por las implicaciones sociales, económicas, de salud y condiciones de vida de la población afectada, lo cual tiene un impacto negativo en el desarrollo del país (5).

En Colombia se diagnostican 4.200 casos nuevos cada año, según el Ministerio de Salud y Protección Social. De 1985 a diciembre de 2012 se reportaron 95.187 casos de infección VIH/SIDA y muerte, el 98,5\% fueron reportados por transmisión sexual. Más de la mitad de los casos se reportó para población entre 20 y 39 años, los mayores de 60 años aportaron el 2,3\% de los casos reportados, presentándose un aumento paulatino del número de casos en este grupo poblacional $(20,21)$.

La Organización Mundial de la Salud ha propuesto tomar medidas innovadoras para alcanzar la meta de los objetivos de desarrollo sostenible. Para el caso de la infección VIH/SIDA, el propósito consiste en poner fin a la epidemia para 2030, realizando una labor conjunta con todos los países, trabajando por minimizar los factores de riesgo y mejorando la calidad de vida de los pacientes (22).

Los migrantes son altamente vulnerables a la exposición de enfermedades de transmisión sexual, incluyendo el VIH, y uno de los factores que contribuye a esta vulnerabilidad es el comercio sexual, actividad de presencia relevante en ciudades fronterizas y en las circunstacias de libertad sexual y uso de drogas psicoactivas (23). La alerta de vigilancia en Salud Pública se presentó al relacionar las condiciones de riesgo y la alta frecuencia de pacientes comprometidos (24).

La situación de la epidemia del VIH/SIDA en Latinoamérica, según los datos más recientes de la Organización Mundial de la Salud (OMS), es cada vez más preocupante si se considera que ocupa el cuarto puesto a nivel mundial en función de la tasa de prevalencia y el tercero en cuanto al número total de personas diagnosticadas en las distintas zonas geográficas del planeta (1).

Respecto a África, las condiciones son cada vez más dramáticas: sigue siendo la región más afectada del mundo y allí las consecuencias son catastróficas, puesto que las personas enfrentan una espectativa de vida de sólo 32,7 años. Se considera que el impacto demográfico de la enfermedad es mayor que el causado por la Primera Guerra Mundial (25-29).

Referente a la distribución por género, los porcentajes son idénticos en Latinoamérica, América del Norte y Europa Occidental, registrándose 80 hombres infectados por cada 20 mujeres infectadas, lo cual es considerablemente diferente a la zona Subsahariana, donde se encuentran razon hombre:mujer de 1:1. (1). En Latinoamérica y en los países desarrollados se continúa observando un mayor porcentaje de varones infectados $(19,25)$.

Según el Observatorio para el Seguimiento del VIH/ SIDA del Ministerio de Salud y el Programa Conjunto de las Naciones Unidas sobre el VIH/SIDA (VIH/ MPS-ONUSIDA), en Colombia la epidemia aún se presenta concentrada, con predominio de transmisión sexual específicamente heterosexual, con una creciente participación femenina, de mayor concentración en áreas de mayor densidad poblacional. La distribución por sexo de los casos notificados de VIH muestra una tendencia a la feminización de la epidemia, pasando de $8,2 \%$ a 26,7\%, incrementando el riesgo de transmisión perinatal, que se encuentra cercano al $3 \%$ del total de infectados (30).

En términos generales, se puede afirmar que los 
mecanismos mundiales de respuesta frente al flagelo del VIH han ido mejorando y se han fortalecido a través del tiempo. Esto, gracias al compromiso y participación de diferentes actores como las instituciones públicas y privadas, quienes a través de la gestión de recursos, la elaboración de guías de control y el manejo y la implementación del programa gratuito de tratamiento con antirretrovirales, han convertido este problema de Salud Pública en una responsabilidad de todos (31).

La terapia antirretroviral de alta actividad (TARV) ha logrado disminuir drásticamente la morbimortalidad de la infección por VIH. En Chile y posteriormente en otros países como Colombia, la TARV comienza a administrarse en el sistema público, en 1993, en forma de monoterapia con zidovudina. En 1997 se introduce la biterapia, que se mantiene hasta 1999, cuando se inicia la entrega de triterapia en forma parcial, y en 2002 con una cobertura de 100\% (32).

Pese a que los tratamientos antirretrovirales han prolongado la vida y permitido el aumento en la esperanza de vida de las personas infectadas con el $\mathrm{VIH}$, es claro que los niveles de nuevas infecciones aún son muy altos en el mundo y que, además, el número total de personas que viven con el virus como respuesta a la disminución de la mortalidad, amerita seguir atentos a esta pandemia que, desde finales del siglo pasado, ha modificado sustancialmente los hábitos y conductas del mundo actual (33-39)

En los países americanos, los costos del manejo de los pacientes infectados por VIH/SIDA han mostrado un incremento anual importante, tanto por la atención médica como por la terapia antirretroviral. La atención hospitalaria representa, en los costos, un porcentaje cercano al $40 \%$ del total del manejo (39).

En el Departamento del Quindío y en la empresa promotora de salud (EPS) de estudio, en particular, a pesar de los avances científicos, es un problema relevante la aparición de complicaciones para la salud relacionadas con la presencia de patologías concomitantes al VIH/SIDA, que ocasionan hospitalizaciones y con ello, aumento de los costos en el tratamiento.

Al realizar la revisión de literatura no se hallaron artículos científicos con abordaje específico en el tema, a nivel internacional y nacional, por lo cual no fue posible contrastar las diferencias de costos por complicaciones en pacientes VIH/SIDA; de ahí que el desarrollo de la investigación facilita el reconocimiento de situaciones concretas en cuanto a los pacientes de la EPS y sus situaciones de salud, relacionadas con las hospitalizaciones por complicaciones y los costos que de ellas se derivan.

\section{MATERIALES Y MÉTODOS}

Se realizó un estudio cuantitativo, descriptivo. La población se constituyó con los 52 usuarios de una empresa prestadora de salud (EPS) privada del departamento del Quindío, del programa de VIH. Los pacientes hacían parte del programa ÍNTEGRA (Modelo de Gestión Integral de Servicios de Salud Sexual y Reproductiva y Prevención de la Infección por VIH), de una EPS privada del departamento del Quindío, teniendo en cuenta que dicha institución tiene sede en tres municipios y cuenta con igual número de unidades para atención de pacientes en cada uno de los municipios.

Cuando los pacientes requieren hospitalización son remitidos a las insituciones prestadoras de servicios de salud (IPS) de cada uno de los municipios respectivos y cuando es necesario se derivan a la IPS de la ciudad de Armenia. Se estudiaron 31 pacientes que tuvieron hospitalizaciones durante el periodo julio 2012 -julio 2013, a traves de un muestreo por conveniencia, de tipo consecutivo secuencial. Este tipo de muestreo permitió acceder a la información de la historia clínica de cada uno de los pacientes que ingresó a las instituciones prestadoras de servicios de salud, en calidad de hospitalizados, durante el periodo de estudio.

La unidad de análisis se constituyó con cada historia clínica de los pacientes de VIH, vinculados al programa de la EPS privada. La información incluida en las historias clínicas, se recolectó en una encuesta elaborada por el equipo investigador, denominada Características económicas de las complicaciones que generan hospitalización en los pacientes del programa VIH/SIDA de una EPS privada del departamento del Quindio, Colombia, con inclusión de cada una de las variables contempladas en los objetivos del estudio. El instrumento fue revisado y validado por cinco expertos, entre auditores y epidemiólogos, quienes efectuaron las observaciones pertinentes para la
ISSN 1794-9831

E-ISSN 2322-7028

Vol. 14 No. 1

Ene - Jun 2017

Cúcuta, Colombia 
ISSN 1794-9831

E-ISSN 2322-7028

Vol. 14 No. 1

Ene - Jun 2017

Cúcuta, Colombia transformación de éste. Para determinar su validez y confiabilidad, se aplicó el Alfa de Cronbach, que fue de 0,80 .

Se tomaron en cuenta variables sociodemográficas como edad, sexo y municipio de residencia; variables clínicas como adherencia al programa, complicaciones generadas por la hospitalización, servicio de hospitalización y estado al egreso, y, como variables para medición de costos, dias de hospitalización y valor de la factura. El instrumento manejó 10 ítems, con escalas de respuestas nominales y ordinales.

Para la edad, se recolectó el dato numérico de los años cumplidos; para sexo, se evaluó masculino y femenino; para municipio de residencia se clasificó en pacientes de Montenegro, Calarcá y Armenia, municipios en los cuales brinda atención la EPS. Para adherencia al programa, se estableció la escala de adherente y no adherente; en cuanto a las complicaciones se extrajeron de la historia clinica las de cada paciente hospitalizado.

Para el servicio de hospitalización se tuvo en cuenta el área de internación en la cual fue hospitalizado cada paciente, para el estado al egreso se estableció la escala de vivo o muerto, para medición de costos se tuvieron en cuenta las cifras económicas del valor por costo correspondiente a los tratamientos e insumos utilizados durante la atención de la hospitalización por la complicación, en cuanto a los días de hospitalización se manejo el valor independiente del número de días de internación, para el valor de la factura se tuvo en cuenta el dato numérico en cuanto al registro de la información correspondiente al costo de la factura.

Los criterios de inclusión fueron: ser paciente incluido en la base de datos de la EPS, tener diagnóstico de VIH/ SIDA, haber sido hospitalizado por una complicación durante el periodo de estudio. En la investigación no se contemplaron criterios de exclusión, por cuanto entre los pacientes atendidos en el programa por parte de la EPS privada del departamento del Quindío no se encontraron pacientes pediátricos.

Para este estudio se tomaron como criterios de adherencia la asistencia a más del $90 \%$ de las citas de control del programa de manejo y control de VIH/SIDA de la EPS privada del departamento del Quindío y la inasistencia a más del $10 \%$ de las citas se consideró como criterio de no adherencia. Como criterios de complicaciones, se tuvieron en cuenta las establecidas por los médicos tratantes en las respectivas historias clínicas.

La información fue tabulada en una base de datos creada por los investigadores en el programa Excel, versión 2010, para posteriormente realizar un análisis descriptivo. Los datos obtenidos se analizaron mediante estadística descriptiva, medidas de tendencia central y dispersión.

Para el desarrollo del estudio se acogieron las normas nacionales e internacionales relacionadas con los aspectos éticos para la protección de los derechos de los pacientes involucrados en el estudio, Declaración de Helsinky (40) y Resolución No. 008430 de 1993 (41). Se contó con consentimiento informado institucional, firmado por el representante legal de la institución, previa reunión con el comité de ética e investigación. Por ser una investigación sobre datos secundarios, recolectados en un instrumento aplicado a la historia clínica y a las facturas, no se tuvo en cuenta nombre ni identificación de los pacientes. De esta manera, tampoco se contó con consentimiento informado, por no tener ningun contacto directo con los pacientes.

\section{OBJETIVOS}

\section{Objetivo general}

Determinar las características económicas de las complicaciones que generan hospitalizaciones, en los pacientes del programa de control de la infección causada por el virus de la inmunodeficiencia humana, en una EPS privada del Quindío, durante el periodo julio 2012 - julio 2013.

\section{Objetivos específicos}

- Caracterizar la población de estudio, según edad, sexo y municipio donde recibe el servicio.

- Identificar la distribución de los pacientes hospitalizados por complicaciones, según la adherencia y no adherencia al programa.

- Establecer los costos de las hospitalizaciones por complicaciones en los pacientes del estudio. 


\section{RESULTADOS}

La recolección de la información se realizó durante el primer semestre de 2014. Las limitaciones que se presentaron durante la realización del estudio se relacionaron con el acceso de manera rápida a la información de facturación correspondiente a los costos discriminados por actividades según evento.

\section{Algunas variables sociodemográficas}

Más de la mitad de la población estudiada corresponde al sexo masculino. Del total de hombres, el 40\% (12 pacientes) está entre 41 y 50 años, el 30\% ( 9 personas) tiene menos de 40 años y el mismo porcentaje tienen más de 51. La mitad de las mujeres está entre 31 y 40 años, una de cada cuatro tiene entre 41 y 50 años y una mínima parte se encuentra en los extremos de la pirámide poblacional, con menos de 30 años o más de 51, como se puede observar en la figura 1 . La mayoría de los pacientes corresponde al municipio de Armenia, con un 58\% (18 pacientes); se encontró un $19 \%$, (6 pacientes) del municipio de Calarcá y un 23\% (7 pacientes) de Montenegro.

Figura 1. Pirámide poblacional $(\mathrm{n}=31)$.

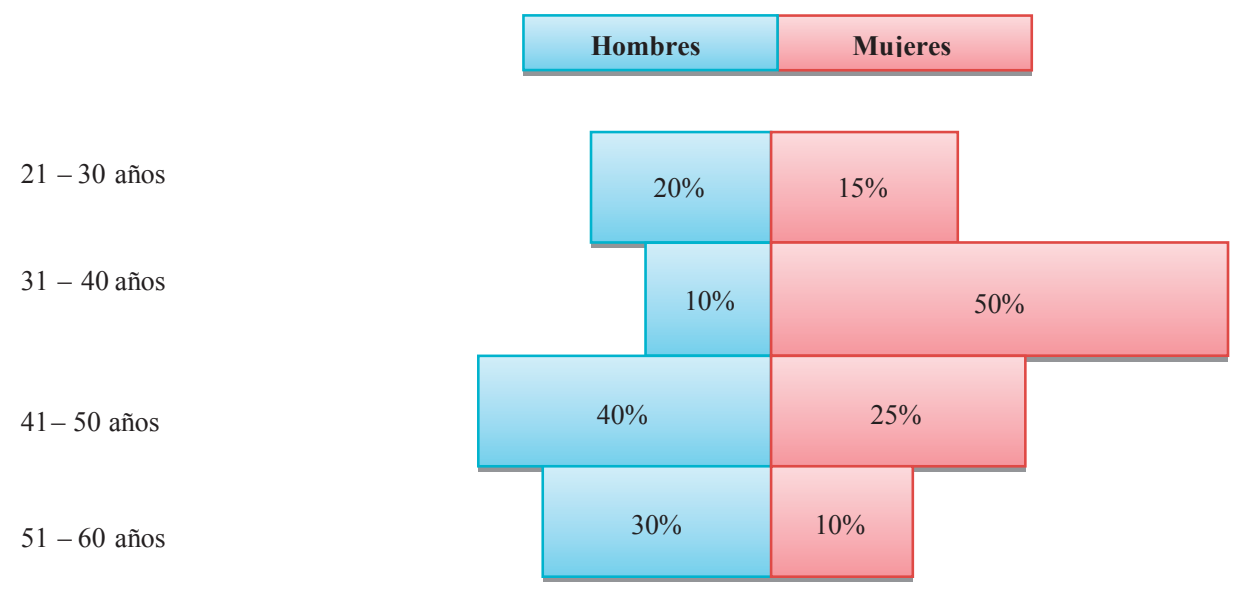

Fuente: Características económicas de las complicaciones que generan hospitalización en los pacientes del programa VIH/SIDA de una EPS privada del departamento del Quindío, Colombia, 2014.

\section{Complicaciones más frecuentes y adherencia al programa}

De los 31 usuarios del programa, por cada seis pacientes que fueron hospitalizados, cinco presentaron adherencia a las actividades de promoción de mejor calidad de vida entre los pacientes y control de los procesos de cuidado y tratamiento. Al realizar el ajuste de proporciones, los pacientes con mayor adherencia fueron los del municipio de Calarcá, partiendo de que para este estudio se tomó, como criterio de adherencia, la asistencia a más del $90 \%$ de las citas de control del programa de manejo y control de VIH/SIDA de la EPS privada del departamento del Quindío, mientras que la inasistencia a más del 10\% de las citas se consideró como criterio de no adherencia.

La figura 2 muestra los diagnósticos de los pacientes de VIH con hospitalizaciones en la EPS privada. Para la variable Complicaciones más frecuentes, según criterios del médico tratante, la toxoplasmosis ocupó un primer lugar con un 22\% (7 pacientes), la neumonía se presentó en el 13\% de los casos (4 pacientes); con igual porcentaje se presentó la enfermedad diarreica aguda, mientras que la gastritis aguda se presentó en 3 pacientes $(10 \%)$. También se presentaron otras
ISSN 1794-9831

E-ISSN 2322-7028

Vol. 14 No. 1

Ene - Jun 2017

Cúcuta, Colombia 
complicaciones como vértigo, candidiasis, cefalea y dengue hemorrágico, entre otras. Un $6 \%$, (2 pacientes respectivamente), presentó el linfoma no Hodking y la fiebre no especificada.

La tasa más alta de hospitalización por complicación del VIH correspondió al municipio de Calarcá, con un 75\% (4 de los pacientes), seguida de Armenia que mostró un 67\% (12 pacientes) y Montenegro con un 41\% (3 pacientes).

La causa más frecuente de hospitalización en pacientes adherentes fue la enfermedad diarreica aguda, mientras que en pacientes no adherentes fue la toxoplasmosis.

Figura 2. Distribución según el diagnóstico de los pacientes con hospitalizaciones del programa de VIH de una EPS privada en el departamento del Quindío.

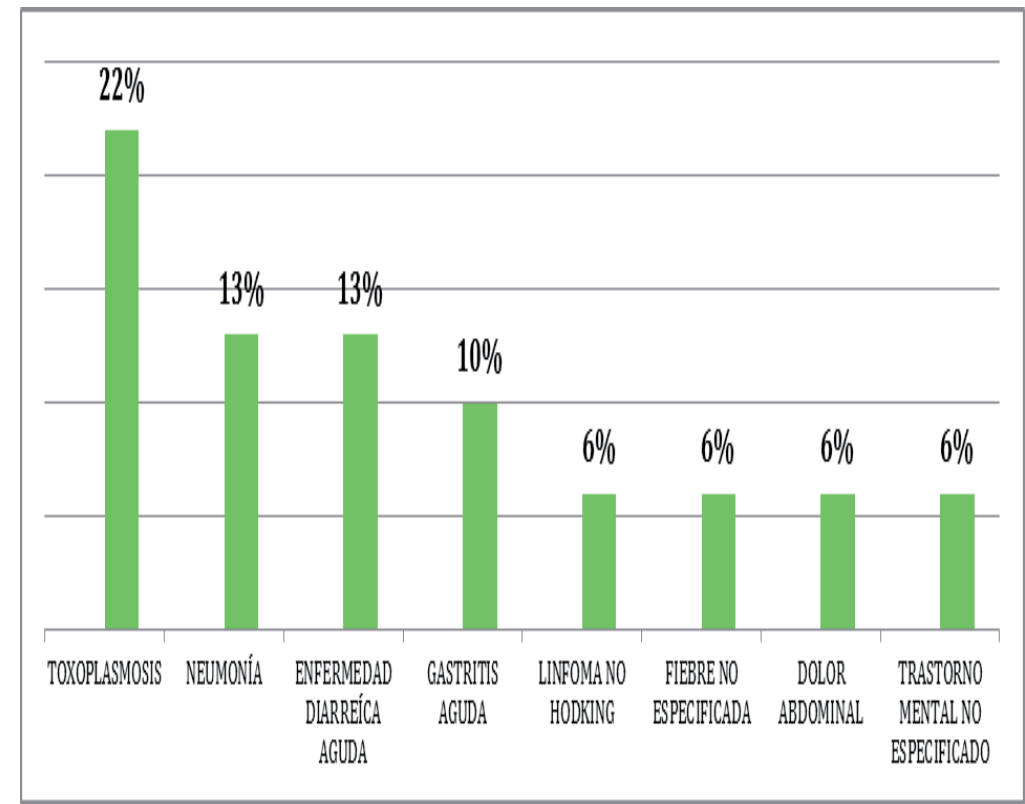

Fuente: Características económicas de las complicaciones que generan hospitalización en los pacientes del programa VIH/SIDA de una EPS privada del departamento del Quindío, Colombia, 2014.

\section{Costos por complicaciones en pacientes hospitalizados}

Teniendo en cuenta los valores de las facturas del total de los pacientes, por el total de días de estancia hospitalaria, los diagnósticos que generan mayores costos son la toxoplasmosis, con $\$ 91.560 .572$ y la neumonía cib \$47.484.466, seguidos del linfoma no hodking con un valor de $\$ 23.223 .859$. El mayor número de días de hospitalización está representado por los pacientes no adherentes al programa de $\mathrm{VIH}$, quienes estuvieron hospitalizados 21,4 días en promedio. De los pacientes que estuvieron hospitalizados, los que tienen menor adherencia al programa son los del municipio de Montenegro, con un porcentaje de no adherencia del 43\% (13 pacientes), lo que puede deberse a la accesibilidad geográfica con la capital Armenia.

El total de pacientes de Calarcá que estuvo hospitalizado es adherente al programa. De los pacientes de Armenia, un 11\% (4 pacientes) evidenció no adherencia al programa. Las hospitalizaciones de los pacientes adherentes al programa son las más costosas, con un valor de $\$ 132.258 .980$, debido a que esta población está conformada por un mayor número de usuarios con respecto a los no adherentes, quienes presentaron un costo de $\$ 69.294 .784$, para un costo total por hospitalizaciones de $\$ 201.553 .764$. 
La complicación más costosa para la EPS está representada por las hospitalizaciones ocasionadas por la toxoplasmosis, cuyo costo medio por evento es de $\$ 15.260 .095$, frente al costo medio evento total que es de $\$ 6.501 .734$ y el costo medio evento sin toxoplasmosis con un valor de $\$ 4.399 .728$, de acuerdo a la tabla 1.

Es de resaltar que ninguno de los pacientes analizados tuvo estancias en Unidad de Cuidados Intensivos durante el periodo de estudio y todos egresaron vivos, lo cual evidencia que, si bien la adherencia al programa no es del $100 \%$ de la población, ésta puede ser un factor protector para aquellos usuarios que sí la tienen, incrementando sus posibilidades de evolucionar satisfactoriamente frente a una complicación de su enfermedad y disminuir la mortalidad por infecciones sobreagregadas.

Tabla 1. Distribución de los diagnósticos, según el costo de la hospitalización de los pacientes del programa de VIH de una EPS privada en el departamento del Quindío.

\begin{tabular}{|l|c|}
\hline \multicolumn{1}{|c|}{ DIAGNÓSTICO } & $\begin{array}{c}\text { COSTO DE LAS FACTURAS } \\
\text { (Total de Pacientes) }\end{array}$ \\
\hline Toxoplasmosis & $\$ 91.560 .572$ \\
\hline Neumonía & $\$ 47.484 .466$ \\
\hline Linfoma no hodking & $\$ 23.223 .859$ \\
\hline Enfermedad diarreica aguda & $\$ 1.785 .185$ \\
\hline Gastritis aguda & $\$ 1.056 .547$ \\
\hline
\end{tabular}

* Se tomaron en cuenta para la tabla los costos superiores a un millón de pesos.

Fuente: Características económicas de las complicaciones que generan hospitalización en los pacientes del programa VIH/SIDA de una EPS privada del departamento del Quindío, Colombia, 2014.

\section{DISCUSIÓN}

A pesar de la exhaustiva búsqueda de otros trabajos sobre costos de complicaciones en pacientes hospitalizados, no se encontraron referencias directas sobre este tema en concreto.

Los resultados delestudio, en relación conel género, y al igual que en estadísticas mundiales (42-43), muestran que los pacientes con mayor representatividad son del sexo masculino, con domicilio en zona urbana. La alta frecuencia de pacientes residentes en el municipio de Armenia puede deberse a que esta es la ciudad capital y concentra la mayor cantidad de los usuarios de la EPS del estudio.

La carga asistencial del VIH/SIDA sigue siendo relevante para el sistema de salud y gestores de recursos sanitarios, por lo cual es importante que se tomen en cuenta todos los aspectos socioculturales, biológicos y de complicaciones que implica la enfermedad, ya que en conjunto ocasionan grandes pérdidas para el paciente, las familias, las instituciones y la sociedad en general.

El departamento del Quindío cuenta con una persona con el virus en tratamiento por cada 785 hogares, según el Departamento Administrativo Nacional de Estadística (DANE) (44) y, con respecto a los datos sociodemográficos del presente estudio, se encuentra que la mayoría de la población investigada pertenece al género masculino, situación coherente con las estadísticas sanitarias a nivel mundial que hablan de un mayor número de casos de infección por VIH en pacientes hombres. Del mismo modo, datos del DANE (44) indican que el $88 \%$ de las personas infectadas y tratadas en el Departamento del Quindío son hombres y el $12 \%$ mujeres, datos concordantes con los resultados de Cajas (43). 
ISSN 1794-9831

E-ISSN 2322-7028

Vol. 14 No. 1

Ene - Jun 2017

Cúcuta, Colombia
Sin embargo, cada día se observa un panorama distinto: las mujeres se van viendo cada vez más afectadas, puesto que son físicamente más vulnerables que los hombres y esta vulnerabilidad acontece principalmente durante las relaciones sexuales, ya que cuando no se usa preservativo es dos veces más probable que se produzca la transmisión del VIH de varón a mujer que a la inversa (45). A esto se suman las desventajas culturales y de género que las afectan, especialmente si son pobres y carecen de educación.

Cabe resaltar que la principal vía de transmisión del $\mathrm{VIH}$, en la mayoría de las regiones, es la homosexual (varones que tienen relaciones sexuales con varones). Por su parte, Latinoamérica, Norteamérica y Europa Occidental comparten esta vía de transmisión, lo cual puede deberse a las influencias en el estilo de vida entre estas áreas geográficas (1). Según la información proporcionada por el Programa Conjunto de las Naciones Unidas sobre el VIH/SIDA (ONUSIDA) (45), se está registrando, en la actualidad, un aumento de los casos de VIH en homosexuales en estas zonas, evidenciando un incremento de las conductas de riesgo en esta población, lo que genera, a su vez, mayor número de varones infectados, quienes posteriormente infectarán a las mujeres y éstas a sus parejas.

Referente al municipio de residencia de los pacientes que estuvieron hospitalizados durante el periodo de estudio, se observa que la mayoría son procedentes de Armenia, seguido de Montenegro y Calarcá, dato que es correspondiente con la cantidad de usuarios que tiene la EPS en cada uno de estos municipios.

Es preciso tener en cuenta que las enfermedades infecciosas y parasitarias son patologías que predominan en el estado de inmunosupresión dado por el VIH/SIDA (38) y se consideran enfermedades oportunistas, porque se aprovechan de la falta de defensas del paciente enfermo y, además, están asociadas con una mortalidad muy alta (46). Al observar las principales complicaciones que generaron hospitalizaciones en la población estudiada, se evidencian como principales causas: la toxoplasmosis, la neumonía, la enfermedad diarreica aguda, la gastritis y el linfoma no hodking.

En cuanto a la adherencia al programa, las cifras muestran que la mayoría de los pacientes que estuvieron hospitalizados son adherentes a este; por cada seis pacientes que presentan hospitalizaciones, cinco son adherentes. La detección temprana y el tratamiento con fármacos cada vez menos tóxicos y más fáciles de tomar pueden mejorar el espectro de las enfermedades oportunistas y complicaciones asociadas al VIH, pero para conseguir un verdadero descenso del SIDA (47), son imprescindibles más campañas de educación, prevención y estrategias de adherencia a los programas, donde se consiga que el $100 \%$ de los pacientes enfermos tengan acceso al tratamiento.

La tasa más alta de hospitalización por complicación del VIH está representada en el municipio de Calarcá. Datos del DANE (44) revelan una relación de un individuo con SIDA por cada 1.772 hogares en este municipio, siendo, en términos generales, el municipio del Quindío con menos personas infectadas, contrario a lo que sucede en el municipio de Armenia, donde la relación es de una persona infectada tratada por cada 664 hogares. Para este estudio, la tasa de hospitalización es mucho más baja.

A pesar de que todos los pacientes de Calarcá son adherentes al programa y que la cantidad de usuarios es inferior con respecto a los otros dos municipios, seis de los ocho pacientes se hospitalizaron por alguna complicación. La causa más frecuente de hospitalización en pacientes no adherentes al programa es la toxoplasmosis; las demás complicaciones se presentaron en pacientes adherentes.

Al comparar estos datos con el costo de las facturas, se encuentra que la complicación que genera mayores costos para la EPS es la toxoplasmosis, con un valor de $\$ 91.560 .572$, lo que representa casi el $50 \%$ del costo total de la facturación durante el periodo de estudio, incidiendo además en la estancia hospitalaria por significar mayor número de casos y de días de hospitalización.

Las cifras del DANE (44) indican que el $0,03 \%$ de la población del departamento del Quindío manifestó estar recibiendo tratamiento para el VIH. En el año 2009, este ente territorial contaba aproximadamente con 202 personas infectadas tratadas, con un costo aproximado de $\$ 3.030$ millones de pesos anuales, lo cual evidencia el impacto económico que esta enfermedad representa para las distintas entidades responsables. De igual manera, el costo de 
sostenimiento médico de las personas infectadas y tratadas en el Eje Cafetero asciende aproximadamente a los $\$ 8.500$ millones de pesos anuales (40).

Al igual que en el estudio de Urueña et al. (48), se encontró que los costos por atención de enfermedades oportunistas incrementan la destinación obligatoria de recursos orientados a la atención de los pacientes con VIH-SIDA.

Pese a que los datos epidemiológicos internacionales más recientes indican que el porcentaje mundial de personas que viven con el VIH se estabilizó desde el año 2000 y que la tasa estimada de mortalidad por SIDA disminuyó debido a los avances farmacológicos y el acceso al tratamiento antirretrovírico, estas tendencias aún son desiguales en diferentes regiones del mundo e indican la imperativa necesidad de impulsar avances integrales que, desde el marco de políticas públicas, garanticen el acceso a los servicios preventivos y curativos, manejo adecuado de la enfermedad de acuerdo con el nivel asistencial y el enfoque de programas de prevención de la enfermedad y de promoción de la salud (49).

El mayor número de días de hospitalización está representado por los pacientes no adherentes al programa. La aparición de nuevos casos de SIDA no lleva el mismo ritmo que hace 10 años, las consultas externas y los hospitales de día absorben buena parte de la demanda, evitan ingresos y recortan las estancias; sin embargo, más de la tercera parte de los casos actuales de SIDA corresponden a individuos que desconocen estar infectados cuando comenzaron con una enfermedad definitoria (47).

Aunque los regímenes de tratamiento se han simplificado, todavía están lejos de ser inofensivos y, por diferentes motivos, una parte de los que toman antirretrovirales no alcanza el éxito terapéutico. Estos factores, sumados a la comorbilidad de los que sobreviven al VIH/SIDA, hacen difícil prever un descenso significativo de los ingresos hospitalarios (47).

De los pacientes que estuvieron hospitalizados, los que tienen menor adherencia al programa son los del municipio de Montenegro, lo que puede deberse a la accesibilidad geográfica con respecto a la capital que es Armenia. Por el contrario, el total de los pacientes de Calarcá que estuvo hospitalizado es adherente al programa. Sin embargo, al comparar este dato con el porcentaje de hospitalización, se encuentra que es la más alta con respecto a los otros dos municipios estudiados.

El VIH/SIDA es una enfermedad que afecta las capas sociales más desfavorecidas y las situaciones de precariedad económica y familiar retrasan el acceso al sistema de salud y limitan el cumplimiento de regímenes terapéuticos indefinidos; en otras palabras, el fracaso virológico por falta de adherencia al tratamiento puede ser elevado, en función de las condiciones sociodemográficas y las barreras de acceso de la población atendida $(47,50)$.

Es de resaltar, que ninguno de los pacientes estudiados tuvo estancias en unidad de cuidado intensivo (UCI) durante el periodo de estudio y que todos egresaron vivos, lo cual demuestra la importancia del acompañamiento a los pacientes VIH/SIDA a través de estos programas, como un factor protector para los usuarios. En concordancia con lo descrito y con la revisión de la literatura, si bien la mortalidad por el SIDA a nivel mundial disminuyó debido a la mejor calidad de atención de los pacientes, ahora se considera que el VIH es una enfermedad crónica (46).

Esta enfermedad constituye un motor enorme de avance científico y tecnológico, impulsando grandes avances para la comprensión y manejo de muchas otras enfermedades y ha llevado, por primera vez en la historia, a que una misma generación de científicos y profesionales de la salud, en su mayoría vigente, haya sido testigo y actor de su aparición, caracterización clínica y fisiopatológica (35).

El manejo de las complicaciones de la enfermedad, el surgimiento de tratamiento específico efectivo para su control y la implementación exitosa de su uso masivo transformaron una enfermedad de alta y rápida mortalidad en una patología crónica, tratable, de larga sobrevida, con buena calidad de vida y reinserción social, laboral y familiar. Está aún pendiente saber si la actual población verá la cura definitiva o la prevención con vacunas efectivas, aun cuando es claro que serán las nuevas generaciones las que asumirán el rol principal de dirigir esos esfuerzos (35).

\section{CONCLUSIONES}

La mayoría de los pacientes que tuvieron hospitalizaciones por complicaciones de la
ISSN 1794-9831

E-ISSN 2322-7028

Vol. 14 No. 1

Ene - Jun 2017

Cúcuta, Colombia 
ISSN 1794-9831

E-ISSN 2322-7028

Vol. 14 No. 1

Ene - Jun 2017

Cúcuta, Colombia enfermedad, pertenecientes a la EPS privada del departamento del Quindío, son hombres jovenes, congruente con el sexo y la edad de los pacientes inscritos en el programa de control para VIH/ SIDA de la institución en estudio y con el comportamiento de la patología en el país y en el mundo.

$\mathrm{Al}$ igual que en la literatura revisada, las principales complicaciones que generaron hospitalizaciones en la población de la EPS fueron la toxoplasmosis -que sigue siendo una complicación de alta frecuencia en todas las latitudes-, la neumonía -que se presenta con bastante frecuencia en todo tipo de población afectada por el VIH/SIDA-, la enfermedad diarreica aguda -que es una condición de suma frecuencia para estos pacientes- y el linfoma no hodking -que también acompaña frecuentemente a este grupo de pacientes-

De acuerdo con los hallazgos, las hospitalizaciones que generan más costos para la EPS son las relacionadas con las patologías antes mencionadas, la toxoplasmosis y la neumonía, siendo la primera la principal causa de hospitalización de pacientes no adherentes al programa de control de VIH/SIDA en esta EPS del departamento del Quindío.

Las complicaciones del VIH/SIDA son costosas, tanto para los pacientes como para sus familias, al igual que para las EPS que cubren los servicios de este grupo de personas. Teniendo en cuenta la susceptibilidad de esta población de contraer patologías, que en otras circunstancias son de fácil manejo, es recomendable mantener la proyección hacia la prevención.

\section{CONFLICTO DE INTERESES}

Los autores declaran no tener ningún conflicto de intereses. 
1. Teva I, Bermúdez MP, Ramiro MT, Buela G. Situación epidemiológica actual del VIH/SIDA en Latino América en la primera década del siglo XXI. Análisis de las diferencias entre países. Rev. méd. Chile 2012; 140(1): 5058

2. Alarid-Escudero F, Sosa-Rubí S, Fernández B, Galárraga O. Análisis de costo-beneficio: prevención del VIH/ sida en migrantes en Centroamérica. Rev. Salud Pública Méx 2013; 55 (Suppl. 1): 23-30.

3. Duesberg P. AIDS Acquired by Drug Consumption and Other Noncontagious Risk Factor. Pharmacology \& Therapeutics. 1992; 55(2): 201-277.

4. Fernández-Prieto, B, Puertas-Álvarez D, Minaberriet-Cruceiro E. Relación entre consumo de drogas y VIH/ SIDA. La Habana, 2012-2013. Revista del Hospital Psiquiátrico de La Habana [Internet]. 2014 [consultado 4 de marzo de 2015]; 11(Suppl 1). Disponible en: http://www.medigraphic.com/pdfs/revhospsihab/hph-2014/ hphs141ze.pdf

5. Chacón-Quesada T, Corrales-González D, Garbanzo-Núñez D, Gutiérrez-Yglesias JA, Hernández-Sandí A, Lobo-Araya A, Romero-Solano A, et al. ITS Y SIDA en adolescentes: descripción, prevención y marco legal. Med. leg. Costa Rica [Internet]. 2009 [consultado 15 de mayo de 2015]; 26(2): 79-98. Disponible en: http:// www.oalib.com/paper/2377347\#.V1mojObhDJw

6. Programa Conjunto de Naciones Unidas sobre el VIH/SIDA (ONUSIDA). Ampliar la respuesta mundial al VIH través de una acción orientadora: reducir el riesgo y la vulnerabilidad. Definiciones, justificaciones y vías. Ginebra: OMS; 1998.

7. Bolaños-Gutiérrez MR. Implicaciones éticas, legales y sociales del diagnóstico de VIH/SIDA en la mujer. Revista Cubana de Salud Pública 2013; 39(1): 124-134.

8. Sardiñas-Ponce R. Actualización sobre el virus de inmunodeficiencia humana y el síndrome de inmunodeficiencia adquirida: sus implicaciones para el uso clínico. MediSur 2010; 8(3): 33-39.

9. Chávez-Rodríguez Edilberto, Castillo-Moreno Rosa del Carmen. Revisión bibliográfica sobre VIH/SIDA. Multimed. 2013; 17(4): 20-21.

10. Mesa-Mazo MJ, Vergaño-Salazar JG, Sánchez-Botero CE, Muñoz-Loaiza A. Modelo matemático para la dinámica de transmisión del VIH/SIDA en una población sexualmente activa. Rev. de Salud Pública. 2010; 12(2): 308-316.

11. Centers for Disease Control and Prevention (CDC). Revision of the CDC surveillance case definition for acquired immunodeficiency syndrome. MMWR. 1987; 36(1): 1s-15s.

12. U.S. Department of Health and Human Services, Health Resources and Services Administration, HIV/AIDS Bureau. Guide for HIV/AIDS Clinical Care. [Internet]. Rockville, MD,U.S: HRSA; 2014 [consultado 18 de junio de 2016]. Disponible en: http://aidsetc.org/sites/default/files/resources_files/Clinical_Manual 4-30-2014_0.pdf

13. Tavera M. Calidad de vida relacionada a la salud en pacientes con VIH. Revista Peruana de Epidemiología. [Internet]. 2010 [consultado 7 de junio de 2015]; 14(3): 170-176. Disponible en: http://www.redalyc.org/ articulo.oa? id=203119676002.

14. Acosta AM, Morales A, Gutiérrez MÁ, Piñera A. Epidemia de VIH/SIDA. Su comportamiento municipio La Habana Vieja períodos 1997- 2002 y 2003-2008. Rev haban cienc méd [Internet]. 2012 [consultado 25 de abril de 2016]; 11(2): 281-290. Disponible en: http://scielo.sld.cu/scielo.php?script=sci arttext\&pid=S1729519X2012000200014\&lng=es

15. Teva I, Bermúdez MP, Hernández-Quero J, Buela-Casal G. Calidad de vida relacionada con la salud en la infección por el VIH. Psicología y Salud [Internet]. 2004 [consultado 30 de agosto de 2016]; 14(2): 229-235. Disponible en: http://www.uv.mx/psicysalud/Psicysalud_14_2/14_2/GBuela.html

16. Uribe AF, Valderrama L, Sanabria AM, Orcasita L, Vergara T. Descripción de los conocimientos, actitudes, susceptibilidad y autoeficacia frente al VIH/SIDA en un grupo de adolescentes colombianos. Pensamiento Psicológico [Internet]. 2009 [consultado 30 de mayo de 2015]; 5(12): 29-44. Disponible en: http://www. redalyc.org/articulo.oa?id=80111899003.

17. Trejos-Herrera AM, Mosquera-Vásquez M, Tuesca-Molina R. Niñez afectada con VIH/SIDA: Calidad de vida, funcionalidad familiar y apoyo social en cinco ciudades colombianas. Salud Uninorte [Internet]. 2009 [consultado 30 de mayo de 2015]; 25(1): 17-32. Disponible en: http:/www.redalyc.org/articulo.oa?id=81711840003

18. Infosida.es. Las pruebas clásicas para detectar el VIH. Janssen-Cilag S.A. [Internet]. 2014 [consultado 24 de mayo de 2015]. Disponible en: http://www.infosida.es/las-pruebas-del-vih/las-pruebas-clasicas-para-vih-sida

19. Organización Mundial de la Salud (OMS). VIH/SIDA Nota Descriptiva No. 360. Noviembre de 2015. [Internet]. 2015 [consultado 18 de junio de 2015]. Disponible en: http://www.who.int/mediacentre/factsheets/fs360/es/ 
ISSN 1794-9831

E-ISSN 2322-7028 Vol. 14 No. 1 Ene - Jun 2017 Cúcuta, Colombia
20. Organización Mundial de la Salud (OMS). Campañas mundiales de salud Pública. Día Mundial del Sida 2015 - 1 de diciembre de 2015. [Internet]. 2015 [consultado 3 de marzo de 2016]. Disponible en: http://www.who.int/ campaigns/aids-day/2015/event/es/.

21. República de Colombia, Ministerio de Salud. Boletín epidemiológico, situación del VIH/SIDA en Colombia 2013. Bogotá D.C: Minsalud; 2013.

22. González-Sol M, García-Milian AJ, Alonso-Carbonell L, Reid-Armenteros L. Consumo y costo de medicamentos antirretrovirales utilizados para el tratamiento de pacientes con VIH/sida La Habana, 2009-2013. INFODIR. 2014; 18: 27-40.

23. Alarid-Escudero F, Sosa-Rubí SG, Bertha Fernández B, Galárraga O. Análisis de costo-beneficio: prevención del VIH/sida en migrantes en Centroamérica. Salud Pública Mex. [Internet]. 2013 [consultado 3 de marzo de 2016]; 55(1): S23-S30. Disponible en: http://europepmc.org/articles/PMC3914404?

24. Este es el panorama del VIH/SIDA en Colombia. Revista Semana [Internet]. Martes 24 de abril de 2012. [consultado 2 de mayo de 2014]; Vida Moderna. Disponible en: http://www.semana.com/vida-moderna/ articulo/este-es-el-panorama-del-vih-sida-en-colombia/256926-3

25. Hernández RD, Sánchez G, Juárez C, Pelcastre B, Juárez C. Del riesgo a la vulnerabilidad. Bases metodológicas para comprender la relación entre violencia sexual e infección por VIH entre migrantes clandestinos. Salud Mental 2005; 28(5): 20-26

26. Popovic M, Sarngadharan MG, Read E, Gallo RC. Detection, isolation, and continuous production of cytopathic retropvirus from patients with AIDS and pre-AIDS. Sciencie, New series 1984; 224 (4648): 497-500.

27. Programa Conjunto de Naciones Unidas sobre el VIH/SIDA (ONUSIDA). Reporte global de la epidemia de VIH/SIDA. 2014. Hoja informativa. Ginebra; ONUSIDA; 2014.

28. Zapata-Garibay R, González-Fagoaga JE, Rangel-Gómez MG. Mortalidad por VIH/SIDA en la frontera norte de México: niveles y tendencias recientes. Papeles de Población 2014; 20(79):39-71.

29. Franco C, Ferrer H, Sánchez L, Oletta JF. Infecciones oportunistas en individuos VIH hospitalizados. Hospital Vargas de Caracas. 2005-2006. CIMEL 2008; 13(2): 39-44.

30. Colombia, Ministerio de la Protección Social. Decreto 3039 de 2007, agosto 10, por el cual se adopta el Plan Nacional de Salud Pública 2007-2010. Bogotá D.C.: Minprotección; 2007.

31. Fauci A, Clifford-Lane H. Enfermedad por el virus de la inmunodeficiencia humana: sida y trastornos relacionados En: Kasper D, Fauci A, Hauser S, Longo D, Jameson JL, Loscalzo J. Principios de Medicina Interna de Harrison. $19^{\mathrm{a}}$ ed. México: McGraw-Hill Interamericana Editores, S.A. de C.V; 2016. p. 245-253. ISBN 978-607-15-1335-9

32. Afani A, Beltrán C, Gallardo AM, Roessler P, Acevedo W, Vásquez P. Prevalencia de resistencia primaria en pacientes con infección reciente por VIH-1 en Chile. Rev. méd. Chile [Internet]. 2010 [consultado 19 de mayo de 2014]; 138(6): 669-676. Disponible en: http://dx.doi.org/10.4067/S0034-98872010000600002.

33. Buela-Casal G, Bermúdez MP, Sánchez AI, De Los Santos-Roig M. Situación del VIH / SIDA en Latinoamérica Al final del siglo XX: Análisis de las Diferencias entre Países. Rev. méd. Chile [Internet]. 2001 [consultado 27 de mayo de 2015]; 129(8): 944-954. Disponible en: http://www.scielo.cl/scielo.php?pid=s0034$98872001000800015 \&$ script $=$ sci arttext

34. Molina L. Los grandes avances del sida no son para pobres. Periodismo humano [Internet]. 18 de Mayo de 2010 [consultado 27 de mayo de 2015]. Disponible en: http://periodismohumano.com/cooperacion/unresultado-positivo-era-una-sentencia-de-muerte.html

35. Arrivillaga-Quintero M. Análisis de las barreras para la adherencia terapéutica en mujeres colombianas con VIH/sida: cuestión de derechos de salud. Salud pública Méx [Internet]. 2010 [consultado 26 de mayo 2015]; 2(4): 350-356. Disponible en: http://www.scielo.org.mx/scielo.php?script=sci_arttext\&pid=S0036$\underline{36342010000400011 \& \operatorname{lng}=\mathrm{es}}$

36. Persaud D, Gay H, Ziemniak C, Chen YH, Piatak MJr, Chun TW, et al. Absence of detectable HIV-1 viremia after treatment cessation in an infant. N Engl J Med 2013; 369: 1828-35.

37. Wolff-Reyes M. SIDA: una travesía desde la impotente desesperanza al éxito terapéutico. Rev. chil. infectol. [Internet]. 2015 [consultado 25 de abril de 2016]; 32(Suppl. 1): 9-16. Disponible en: http://www.scielo.cl/pdf/ rci/v32s1/art02.pdf

38. Chávez-Dulce GR, Bolaños-López HA, Sánchez HF, Gómez S. Gérmenes oportunistas en infección pulmonar asociadas a pacientes con VIH/SIDA. Hospital Universitario Departamental de Nariño. 2006-2008. Rev Univ. salud. [Internet]. 2011 [consultado 23 de abril de 2015]; 13(2): 50-59. Disponible en: http://www.scielo.org. co/scielo.php?script=sci arttext\&pid=S0124-71072011000200006\&lng=es.

39. Republica de México, Secretaría de Salud. Manual de Procedimientos Estandarizados para la Vigilancia 
Epidemiológica del VIH/SIDA. [Internet]. Ciudad de México: Secretaría de Salud; 2012 [consultado 20 de mayo de 2014]. Disponible en: http://www.epidemiologia.salud.gob.mx/doctos/infoepid/vig_epid manuales/30_2012_Manual_VIH-SIDA_vFinal_1nov12.pdfç

40. Asociación Médica Mundial (AMM). Declaración de Helsinki. 18 ${ }^{\mathrm{a}}$ Asamblea Médica Mundial. [Internet]. Helsinki, Finlandia; AMM; 1964 [consultado 15 de junio de 2014]. Disponible en: http://www.wma.net/ es/30publications/10policies/b3/index.html.pdf?print-media-type\&footer-right=[page]/[toPage]

41. República de Colombia, Ministerio de Salud. Resolución $N^{\circ} 008430$ de 1993, octubre 4, por la cual se establecen normas científicas, técnicas y administrativas para la investigación en Colombia. Bogotá D.C.: Minsalud; 1993.

42. Broder S. The development of antiretroviral therapy and its impact on the HIV-1 / AIDS pandemic. Antiviral Res. 2010; 85:1-18.

43. Cajas-Crespo T. Estudio epidemiológico de enfermedades oportunistas en pacientes con Vih/Sida. Hospital "Dr. José Garcés Rodríguez" cantón Salinas. Periodo 2009-2013. [Tesis en Internet]. Guayaquil, Ecuador: Universidad de Guayaquil; 2016 [consultado 20 de octubre de 2016]. Disponible en: http://repositorio.ug.edu. ec/handle/redug/11139

44. República de Colombia, Departamento Administrativo Nacional de Estadística (DANE). Gran Encuesta Integrada de Hogares GEIH - 2009. [Internet]. 2009 [consultado 30 de junio de 2014]. Disponible en: http:// formularios.dane.gov.co/Anda 4 1/index.php/catalog/207

45. Organización de las Naciones Unidas - Colombia (ONU), Programa Conjunto de Naciones Unidas sobre el VIH/ SIDA (ONUSIDA). Informe Sida en cifras 2013. [Internet]. 2014 [consultado 23 de mayo de 2014]. Disponible en: http://nacionesunidas.org.co/biblioteca/tag/onusida/

46. Alvarado-García E. El VIH/SIDA y las enfermedades crónicas. [Internet]. 2013 [consultado 30 de agosto de 2016]. Disponible en: http://www.voicesofyouth.org/es/posts/el-vih-sida-y-las-enfermedades-cronicas-

47. Muga R. La larga sombra del VIH/Sida en los Hospitales. Rev. Medicina Clínica. [Internet]. 2004 [consultado 30 de agosto de 2016]; 122(1). Disponible en: http://www.elsevier.es/es-revista-medicina-clinica-2-articulo-lalarga-sombra-del-vih-sida-13056176

48. Urueña-Durán JP, Salazar-Duarte SJ, Ojeda.Quintero LP, Mantilla-Reyes T. Estudio de los costos en que incurren las entidades promotoras de salud en Colombia por la prevención y el tratamiento del VIH/sida. CIEN. TECNOL. SALUD. VIS. OCUL. . [Internet]. 2016 [consultado 20 de octubre de 2016]. 12(1): 51-63. Disponible en: http://revistas.lasalle.edu.co/index.php/sv/article/view/2653/2432

49. Trejos-Herrera AM, Mosquera-Vásquez M, Tuesca-Molina R. Niñez afectada con VIH/SIDA: Calidad de vida, funcionalidad familiar y apoyo social en cinco ciudades colombianas. Salud, Barranquilla [Internet]. 2009 [consultado 30 de agosto de 2016]; 25(1): 17-32. Disponible en: http://www.scielo.org.co/scielo.php?script=sci arttext\&pid=S0120-55522009000100003\&lng $=$ pt.

50. Maurera-Peña E, Reyes-Herrrera Y, Guerrero JM, Herde JD, Capriles-Wehrmann AE, Díaz Solano-MS, et al. Epidemiología de la infección por HIV / SIDA en el Servicio de Medicina Interna III del Hospital Vargas de Caracas. Med Interna (Caracas) [Internet]. 2011 [consultado 30 de mayo de 2015]; 27(2): 137-143. Disponible en: http://svmi.web.ve/wh/revista/V27_N2.pdf\#page $=63$ 